\title{
16 Rückblick und Ausblick - Die Zukunft der Herkulanischen Papyrologie
}

\begin{abstract}
... Vielleicht werden mit dem Fortschreiten all dieser Arbeiten, die eine unendliche Geduld, eine besondere Art von Scharfsinn und ein Gutteil Glück erfordern, noch ganze Gedichte wiedergeboren werden ... Weitaus das Meiste und wahrscheinlich das Schönste ist verloren. Ist vorläufig verloren. Wenn einmal ein Zeitalter anbrechen sollte, in dem die Kulturvölker gesonnen sind, sich dieses Namens würdig zu erweisen, wenn einmal ein Bruchteil der Geisteskraft und der Geldmittel, die bislang auf die Erfindung und den Bau von Vernichtungswaffen verwandt wurden, in den Dienst einer beglückenden und bereichernden Forschung gestellt werden sollte, dann könnte der wunderbare Schatz ... gehoben werden. Wir wissen, daß dieser Schatz vorhanden ist, wir wissen auch, wo er ruht. Aber wir können ihn nicht heben. Er ruht nämlich unter der Lava, die sich einst über die alte Straße von Pompeji nach Herkulaneum ergossen hat, er ruht in den Landsitzen der reichen Römer, die an dieser Straße standen, er ruht in den Bibliotheken dieser Landsitze. Wir können ihn nicht heben, weil niemand das Geld für die Beseitigung der meterdicken Lavamassen zur Verfügung stellt, und wir können ihn nicht heben, weil die Chemie noch kein brauchbares Verfahren entwickelt hat, das die verbrannten Rollen, wenn man ihrer erst einmal habhaft geworden ist, vor dem Zerfall und die Schrift vor dem Vergehen bewahrt. Die Rückständigkeit der Chemie erklärt sich daraus, daß die Nachfrage nach einem solchen Verfahren bislang nicht so drängend war wie die Nachfrage etwa nach einer Atombombe.
\end{abstract}

Manfred Hausmann, Das Erwachen (1949)

Etwa 200 Jahre nach Entdeckung der Herkulanischen Rollen spricht aus diesen Zeilen die ungebrochene deutsche Liebe zur Antike, es spricht die Sehnsucht nach dem Wahren, Schönen und Guten, die Hoffnung auf Geistesschätze, welche von allen Wirren der Zeiten unberührt bleiben, deren Majestät die unvollkommene Gegenwart überstrahlt und für deren Bergung keine Mühen zu scheuen sind. In den Zeilen hallt das Echo der Goethezeit mit ihrer Antikenbegeisterung wider, einer zutiefst leidenschaftlichen Begeisterung, die durch die Funde in Herkulaneum entscheidend mitentfacht wurde und deren segensreiche Ausläufer noch lange nach Goethe Kultur und Geistesleben Deutschlands und Europas prägten. Bei aller objektiv wissenschaftlichen Bedeutung schon entdeckter und noch zu entdeckender Literatur aus Herkulaneum hatten das Lesen und die Suche nach den Papyri auch immer eine tiefere, menschlich-psychologische Dimension: Neugier und Entdeckerfreude, die Erwartung umstürzender Erkenntnisse, das Verzweifeln über das scheinbar zum Greifen Nahe und doch so Ferne, das Enträtseln von Geheimnissen, die Unsicherheit menschlichen Wissens (wenn die Buchstaben des Originals vor den Augen des Lesers verschwinden, Unsichtbares digital sichtbar wird oder sich philologische Ergänzungen als zweifelhaft herausstellen), die Fragilität unserer 
Existenz (versinnbildlicht durch die zerfallenden Papyrusrollen oder das Inferno des Vesuvausbruchs), das Graben nach tief im Inneren verschütteten Wahrheiten, das Wiederentdecken von Literatur, die für Menschen aller Zeiten geschrieben wurde und uns einen Hauch von Ewigkeit verspüren lässt.

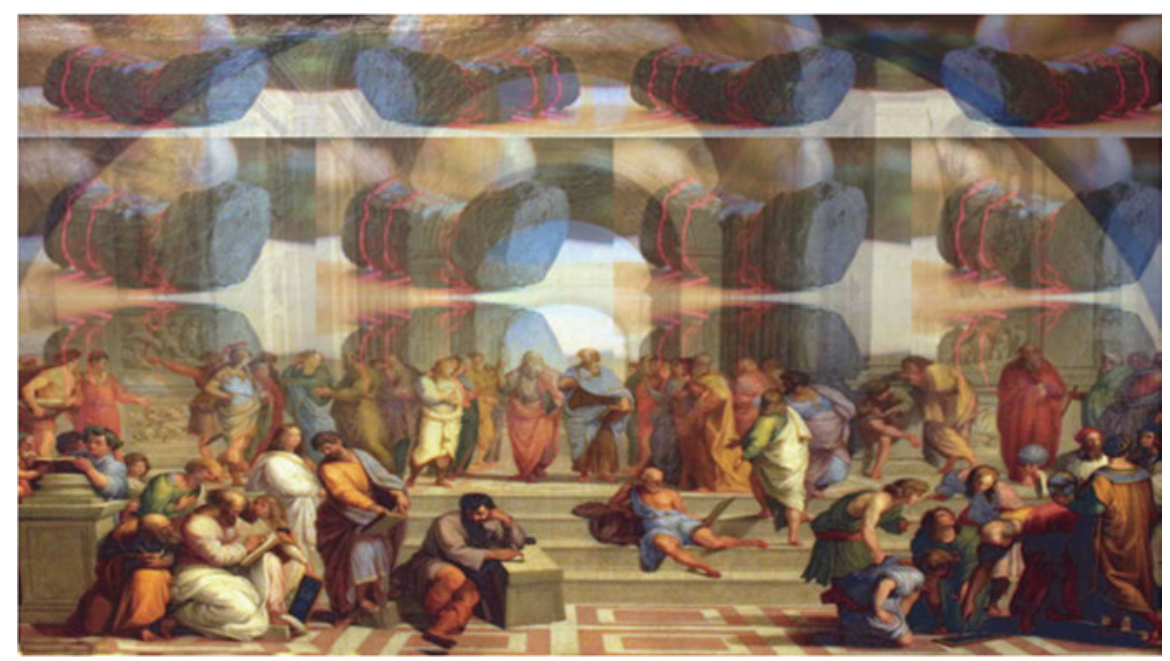

Abb. 63: Die Herkulanischen Papyri und Antike Philosophie

Mit dem vorliegenden Büchlein sollte für einen weiteren akademischen Interessentenkreis kompakt in die Herkulanischen Papyrologie eingeführt werden und eine erste Orientierung zu aktuellen technischen und philologischen Entwicklungen gegeben werden. Die Geschichte der Papyri, ihrer Aufrollung und Herausgabe ist weniger Fachgeschichte als Kulturgeschichte. Entgegen landläufiger Meinung ist die Herkulanische Sammlung alles andere als erschöpft und weist auch inhaltlich über Epikur und Philodem hinaus. Ich habe mich bemüht, dass textuelle Potential und die inhaltliche Spannbreite aufgerollter sowie unaufgerollter Papyri aufzuzeigen. So ist auch von bereits aufgerollten Papyri textuell noch Neues zu erwarten. Der Fortschritt bei in den letzten zwei Dekaden erschienen Neuausgaben von früher bereits edierten Papyri ist einerseits dem Umstand zu verdanken, dass wir nun mit den Multispektralbildern (Hyperspektralbildern) mehr sehen können als mit dem bloßen Auge. Andererseits wurden exaktere Verfahren zur bibliometrischen Rekonstruktion und ausgefeilte Editionsmethoden entwickelt, während digitale Hilfsmittel vieles vereinfa- 
chen oder erst ermöglichen. Neulesungen implizieren nicht selten ein neues Verständnis von Passagen und gehen mit neuen Fakten einher. Philodems Index Academicorum ist hierfür ein besonders ausgeprägtes Beispiel. Noch größeres Potential als in den aufgerollten Papyri dürfte in den hunderten noch ungeöffneten Rollen der Sammlung schlummern. Diese könnten schon in naher Zukunft mittels virtual unrolling geöffnet und gelesen werden. Allein die Wiederentdeckung und Wiederherstellung des Inhalts dieser vom Vesuv konservierten, schon ausgegrabenen, aber noch geschlossenen Rollen hätte wohl eruptive Wirkung über den Bereich der Altertumswissenschaften hinaus. Dass größte Potential für neue Literatur dürfte noch unausgegraben in der Villa zu lokalisieren sein. Es ist im Bereich des Möglichen, dass die lateinische Bibliothek bisher noch nicht gefunden wurde und auch in den anderen Etagen oder Räumen der Villa dei papiri griechische oder lateinische Rollen untergebracht waren. Zwar profitieren moderne Textausgaben in erheblichem Maße von technischen, philologischen und digitalen Innovationen, aber diese können nicht die eigentliche philologische Denk- und Kombinationsarbeit eines Papyrologen bei der Neuedition und Interpretation der Texte ersetzen.

Die Herkulanischen Papyrologen sehen sich gegenwärtig im Lichte neuer Techniken und Methoden Entwicklungen gegenüber, an deren Ende wohl viele neue oder verbesserte antike Texte stehen, welche für die gesamte Altertumswissenschaft und benachbarte Disziplinen von immenser Bedeutung sind. Wir dürfen hoffen - wenn nicht auf eine zweite Renaissance, so doch auf die Wiedergeburt vieler antiker Werke. 